\title{
Incertidumbre y actitudes pro-redistributivas: mercados de trabajo y modelos de bienestar en Europa
}

\author{
Antonio Martín-Artiles, Oscar Molina y Pilar Carrasquer ${ }^{1}$ \\ Universitat Autonoma Barcelona \\ antonio.martin@uab.es - oscar.molina@uab.es - pilar.carrasquer@uab.es
}

Recibido: 12-01-2015

Aceptado: 29-10-2015

\begin{abstract}
Resumen
La articulación entre las políticas de empleo y las políticas sociales condicionan la percepción subjetiva de incertidumbre los individuos. El modelo de mercado laboral tiene un peso determinante en la percepción de incertidumbre. El empleo en sí mismo ya no es suficiente garantía de ingresos seguros. El empleo a tiempo parcial y los contratos temporales generan una creciente demanda de políticas de redistribución de los ingresos en los países del Sur y Este de Europa. En los países escandinavos los mismos tipos de contratos laborales generan menos desigualdad porque el empleo público contribuye a generar un "círculo virtuoso" que favorece las políticas de igualdad y la conciliación entre la vida laboral y familiar. A nivel individual las actitudes pro-redistributivas las impulsan las mujeres, aquellas personas con incertidumbre en sus ingresos económicos y con bajo nivel de estudios. Por el contrario, quienes más confían en el éxito individual y el mérito son los jóvenes con estudios universitarios y aquellos que perciben ingresos económicos altos.
\end{abstract}

Palabras claves: desigualdad; desempleo; trabajo a tiempo parcial; contratos temporales; protección social; gastos en desempleo.

\section{Uncertainty and Attitudes Pro-redistributive: Labour Market and Welfare Models in Europe}

\begin{abstract}
The link between employment policies and social policies influence the subjective perception of individual uncertainty. The labor market model has an important role on the perception of uncertainty. Employment in itself is not enough insurance guarantee income. Part-time work and temporary contracts generates a growing demand for policies of income redistribution in the South and Eastern Europe. In Scandinavia countries the same types of labor contracts generate less inequality because government employment contributes to a "virtuous circle" that favors equality policies and the reconciliation of work and family life. Individually pro-redistributive attitudes are implemented more by women, also for those with uncertainty in their income and low education. By contrast, those who rely more on individual success and merit are the young college-educated and those earning higher incomes.

Key words: inequality; unemployment; part-time work; temporary contracts; social protection expenditure; expenditure on unemployment.
\end{abstract}

1 Centre Estudis Quit/Insitut Estudis del Treball. Departament Sociologia Universitat Autònoma Barcelona. 


\section{Referencia normalizada}

Martín-Artiles, A., O. Molina y P. Carrasquer (2016): "Incertidumbre y actitudes pro-redistributivas: mercados de trabajo y modelos de bienestar en europa", Política y Sociedad, 53 (1), pp. 187-215.

Sumario: Introducción. 1. Breve revisión de la literatura. 2. Metodología. 3. Resultados. 4. Conclusiones. 5. Bibliografía. 6.Anexos.

\section{Introducción}

Los momentos de crisis parecerían ser favorecedores de una mayor demanda de solidaridad y de redistribución. Pero desde hace ya un tiempo se viene discutiendo la crisis de la solidaridad como valor. Algunos estudios sostienen que el incremento de las desigualdades generadas por el mercado de trabajo podría mitigarse mediante políticas redistributivas. Dichos estudios suelen identificar una serie de variables que determinan la demanda de redistribución, entre otras: el Producto Interior Bruto per cápita, la presión fiscal, el gasto social, la tasa de desempleo, así como el empleo precario, el trabajo a tiempo parcial, los contratos temporales y la presencia de los working poor (Breznau, 2010; Dallinger, 2010; Rueda, 2014).

Otras investigaciones han estudiado el papel que juega la redistribución y el mercado de trabajo en los distintos modelos de Estados de Bienestar. En este sentido se ha analizado el papel que juegan las pensiones por desempleo, las pensiones por jubilación, los subsidios y transferencias a las familias para mitigar las desigualdades generadas por el mercado de trabajo (Jensen, 2012; Gërxhani y Koster, 2012; Schmidt-Catran, 2014). Finalmente, otra línea de trabajo se centra en las actitudes de los individuos, entre la cual destaca la idea de la rebelión fiscal de las clases medias (Galbraith, 1992), lo que está asociado con el auge del individualismo (Peetz, 2010) y la crisis de los valores solidarios. En otras palabras, la "crisis del compromiso igualitario" (Schwartz 2007).

En suma, en los últimos años ha venido creciendo el interés por explorar la influencia de las variables contextuales en la conformación de la opinión pública, así como su combinación con la posición y las características de los individuos, lo que ha contribuido al interés por el análisis multinivel (Mau et al., 2012; Wren y Rehm, 2012; Huber y Stephens, 2014).

Este enfoque basado en análisis multinivel está aún poco explorado, razón por la cual consideramos necesario indagar cuáles son los elementos contextuales que contribuyen a explicar la demanda de solidaridad: por un lado, el papel que juega el mercado de trabajo y, por otro lado, el papel que juega el modelo de bienestar en mitigar las desigualdades, así como su interacción con las características de los individuos.

En este sentido nos proponemos dos objetivos:

El primer objetivo es estudiar qué factores influyen en la demanda de redistribución. Interesa ver cómo influyen dichas variables en el grado de incertidumbre en los 
ingresos económicos y cómo dicha incertidumbre influye, a su vez, en la demanda de políticas pro-redistributivas. La crisis económica ha incrementado la percepción de incertidumbre de los ciudadanos europeos. Empero, la demanda de redistribución es desigual entre países, lo que está probablemente ligado a las distintas políticas sociales y a la existencia de diferentes modelos de bienestar.

El segundo es explorar las similitudes y diferencias en los modelos de mercado de trabajo y bienestar y su impacto en la demanda de redistribución. Por lo general la literatura suele tomar como referencia los modelos teóricos de bienestar siguiendo el hilo conductor de estudios ya conocidos (Esping-Andersen, 2000, 2014; Menz, 2008; Bosch et al., 2009, entre otros). Nuestro propósito es afinar en dicha posible interrelación, destacando ciertas variables relativas al mercado laboral y su relación con otras vinculadas con la corrección de las desigualdades sociales y la provisión de seguridad.

Nuestra hipótesis de partida es que la percepción de incertidumbre está mediada por el contexto del mercado de trabajo y de bienestar, de modo que una misma y determinada figura laboral contractual genera distintos efectos de incertidumbre según el contexto. Probablemente el contrato de trabajo a tiempo parcial tiene distintos efectos sobre la demanda de redistribución según el modelo de empleo y de bienestar.

El primer hallazgo de este estudio es que la percepción de incertidumbre y la actitud hacia la redistribución no dependen exclusivamente de las figuras laborales contractuales, sino del modelo de mercado de trabajo y de la importancia del empleo público. El trabajo a tiempo parcial, genera tres distintos tipos de incertidumbre y de demanda de redistribución según el régimen de género y de bienestar que en el que se inscribe:

1) En los países escandinavos, el trabajo a tiempo parcial se ha expandido en un contexto de "des-mercantilización" y de "des-familiarización" apoyado en un potente sistema de protección social y de bienestar, lo que se explica por el volumen de empleo público (Esping-Andersen, 2000, 2014; Campillo, 2010).

2) En los países centro europeos, como Alemania, el trabajo a tiempo parcial, en particular, el tiempo parcial "marginal" (Klammer, 2000) es una respuesta a la dificultad de inserción laboral femenina desde finales de los años noventa, en el contexto de un orden de género tradicional apenas revisado, aunque se ha tratado de mitigar la incertidumbre de los bajos ingresos mediante transferencias y ayudas sociales a los individuos (Keller y Seifert, 2013).

3) En los países del Sur de Europa, el trabajo a tiempo parcial es un componente esencial del empleo precario y de una situación sobrevenida con la actual crisis financiera, además de un exponente de las desigualdades de género que comparte con el resto de modelos. En los países del Sur el trabajo a tiempo parcial apenas cuenta con ayudas y transferencias a las familias y a los individuos (Jepsen, 2000).

Un segundo hallazgo es que la demanda de políticas pro-redistributivas asemejan a los países del Sur y Este de Europa, con una clara diferencia respecto a los países escandinavos y Holanda. Las variables predictivas que tienen más peso determinante son las que están más relacionadas con el modelo de mercado laboral que con el 
modelo de bienestar, la varianza explicada en el análisis de regresión demuestran este argumento. No obstante, podemos colegir la importancia que tiene la política social como correctora de la incertidumbre en los ingresos salariales que genera el empleo atípico y precario emergente en muchos países.

Este artículo se divide en tres secciones. En la primera planteamos una breve revisión de la literatura, en la segunda tratamos la metodología y las variables utilizadas y en la tercera aportamos los resultados, seguido de una serie de conclusiones.

\section{Breve revisión de la literatura}

La demanda de redistribución está relacionada con tres dimensiones. Primero con el modelo de mercado de trabajo, el nivel de desempleo, el empleo precario y la dualización entre empleo protegido y no protegido. En segundo lugar, con el modelo de Estado del Bienestar y su interrelación con el mercado de trabajo. Y, en tercer lugar, con la posición social y las características de las personas. A continuación revisamos sumariamente estas tres dimensiones.

\subsection{Modelo de empleo}

La demanda de reducción de las desigualdades en los ingresos depende del modo de combinación entre la segmentación del mercado de trabajo y el papel que desempeña el Estado del Bienestar. No en todos los países estudiados están articuladas las políticas laborales con las políticas sociales. Una referencia habitual en este tipo de estudios es Alemania, con expansión de los contratos de trabajo atípico (mini-jobs) y las medidas de apoyo mediante subvenciones, desgravaciones fiscales, desgravaciones en las cuotas a la seguridad y transferencias para mitigar los bajos ingresos salariales (Keller y Seifert, 2013). Estas medidas han ido particularmente destinadas a los colectivos de baja cualificación, a los desempleados de larga duración, así como a determinados grupos de mujeres (Klammer, 2000: 576-577). La finalidad de combinar medidas de empleo con medidas redistributivas de bienestar ha tratado de mitigar o incluso evitar el crecimiento de los "working poors", como ocurre en el modelo norteamericano (Ponthieux y Concialdi, 2000). Sin embargo, la actual crisis económica y la política de austeridad parecen haber aumentado las desigualdades y obstaculizado la interacción entre las políticas de empleo y las redistributivas.

Una tesis consolidada en la literatura es que la demanda de redistribución está asociada con el grado de desigualdad en el país (Dallinger, 2010). Pero las desigualdades en los ingresos son toleradas más en unas sociedades que en otras. En las sociedades liberales (Reino Unido, Irlanda, Estados Unidos) la diferencia en los ingresos se asocia al mérito individual, al nivel de cualificación y al esfuerzo, lo que constituye la base de la legitimidad diferencial en los ingresos. En otros países, de tradición "estatista" (Francia) o de tradición política social-demócrata y social cristiana, una fuerte diferencia en los ingresos es menos aceptada socialmente, como en los países escandinavos y Bélgica (Menz, 2008). En todo caso, algunos estudios confirman que en todos los países hay una relación lineal entre desigualdades en los ingresos económicos (índice de Gini) 
y reclamación de intervención del estado para mitigar las desigualdades (Dallinger, 2010:335).

En este sentido, la segmentación del mercado de trabajo constituye un enfoque teórico importante para explicar la estratificación y las desigualdades sociales (Rueda, 2014). El empleo en las sociedades occidentales ha sido un factor clave de integración social, pero en los últimos años el empleo ya no es suficiente por sí solo para garantizar la integración social. Existe un consenso entre los estudiosos de que el desempleo constituye una potencial amenaza de exclusión social y pobreza (Mau et al., 2012). Por ello el desempleo ha ocupado un lugar importante en la literatura económica y sociológica a la hora de discutir el papel que desempeña sobre las actitudes hacia la redistribución de los ingresos. Las altas tasas de desempleo comportan la exigencia de una mayor presión sobre el gasto social, así como una presión fiscal sobre los ingresos de los asalariados para soportar el gasto. El desempleo de larga duración y el agotamiento de la duración de las prestaciones sociales y de los subsidios, está asociado al aumento del riesgo de pobreza y de exclusión social (Jabosen y Listahug, 2012: 398).

El desempleo tiene hoy un especial impacto sobre los jóvenes, sobre los trabajadores con bajas cualificaciones y sobre los inmigrantes. En los estudios comparados, la tasa de desempleo ha sido considerada como uno de los principales factores que influye en el cambio de la opinión pública, en unos casos reclamando soporte a las políticas de creación de empleo y, en otros potenciando la formación de actitudes favorables hacia la movilidad laboral, la responsabilidad individual, la exigencia de formación continua y de empleabilidad (Mau et al., 2012; Huber y Stephens, 2014; Rueda, 2014). Pero también con una opinión pública contraria al aumento de la carga fiscal para financiar al desempleo (Jacobsen y Listhaug, 2012).

\subsubsection{Empleo a tiempo parcial}

El empleo a tiempo parcial en los países escandinavos no parece comportar riesgo de pobreza porque su bajo nivel de ingresos es compensado con políticas de transferencia a las familias (Klammer, 2000; Esping-Andersen, 2000, 2014). Por el contrario, en los países del Sur y Este de Europa parece que el trabajo a tiempo parcial correlaciona con la pobreza y la demanda de redistribución porque la política redistributiva es débil (Campillo, 2010).

Algunos países, como Alemania, han puesto en marcha medidas compensatorias de ayudas para las personas con empleo de pocas horas y de bajos salarios (ubicados en el sector de servicios de baja cualificación) con la finalidad de complementar los bajos ingresos mediante ayudas para la vivienda y el transporte (Keller y Seifert, 2013). La carencia de tales ayudas en otros países ha contribuido a la expansión de los llamados working poor: trabajadores con ingresos inferiores al $60 \%$ del salario medio a pesar de incluso desempeñar más de un empleo. Algunos estudios demuestran que son precisamente estos grupos en riesgo social quienes más reclaman la intervención del Estado para aliviar la precariedad del empleo y los bajos ingresos (Gingrich y Ansell, 2012; OIT, 2014). 


\subsubsection{Empleo protegido y no protegido}

La discusión sobre insiders y outsiders ha ocupado un lugar relevante en la literatura, entre empleos protegidos y empleos no protegidos y precarios (Rueda, 2014). En el caso de los insiders, especialmente para aquellos que tienen empleo en el sector público, los valores colectivos son importantes, pero hipotéticamente menos que para aquellos otros que conforman los outsiders. Quienes tienen empleo público tienen más probabilidades de estar afiliados y protegidos por la acción colectiva de los sindicatos. En contraste, para aquellos quienes tienen empleos precarios y atípicos, las políticas redistributivas constituyen, comparativamente, un factor aún más importante de integración social ante la amenaza del riesgo de exclusión social. En buena medida, las recientes reformas laborales europeas se caracterizan por la tendencia a introducir en todos los países una creciente variedad de empleos atípicos y precarios (Keller y Seifert, 2013: 460), lo que hace hoy políticamente más urgente el debate sobre las políticas redistributivas (Larsen, 2008; Rueda, 2014). Esta urgencia no es sólo para tratar de mitigar las desigualdades en el mercado de trabajo, sino porque también la precariedad en el empleo socaba las propias bases del Estado del Bienestar.

En resumen, hoy, la crisis económica, el desempleo y las formas atípicas de empleo, constituyen factores de presión sobre la opinión pública y, a la vez, sobre las instituciones sociales para desarrollar políticas de protección social, de subsidios y de transferencias económicas a las personas y a las familias con riesgo de pobreza. Este es un aspecto conflictivo en la medida que las políticas de austeridad están llevando a recortar el gasto público, el gasto en pensiones y subsidios por desempleo.

\section{Hipótesis 1.}

A tenor de lo expuesto tratamos de explorar el impacto del empleo atípico, precario y working poor sobre las actitudes hacia la reducción de las desigualdades, lo que planteamos en la siguiente hipótesis.

H:Una mayor proporción de empleos precarios, con bajos salarios, (working poor) contribuye a una mayor demanda de redistribución de los ingresos.

\subsection{Factores institucionales: Estado del Bienestar}

El análisis de los factores institucionales ha recibido recientemente atención en los estudios comparados para tratar de explicar las diferencias entre países. Los factores institucionales se han colocado en el cajón de sastre del llamado "efecto societal". Esta perspectiva focaliza la atención del análisis en los actores sociales, en las instituciones y en su historia, lo que contrasta con el enfoque neofuncionalista que sólo presta atención a los factores estructurales (Menz, 2008). En la literatura sobre la variedad de modelos de bienestar y de capitalismo se suele distinguir cuatro modelos de bienestar. El primero de ellos es el modelo escandinavo, de orientación social-demócrata, que agrupa a países como Suecia, Noruega, Finlandia y Dinamarca (Esping-Andersen, 2000). En otros estudios se incluye también a Bélgica, lo que se conoce como "Ghent System", porque incluye el papel de los sindicatos como otro factor impulsor de la redistribución gracias a la acción colectiva y se genera un "círculo virtuoso entre empleo público, ingresos estables, sindicatos fuertes y bienestar" (Kjellberg, 2009). 
La principal característica es que en dichos países las desigualdades en los ingresos son pocas, gracias a una potente política fiscal redistributiva, auspiciada por sindicatos fuertes y partidos políticos social-demócratas y cristiano-demócratas que impulsan importantes políticas de protección social (Huber y Stephens, 2014).

\section{Hipótesis 2.}

Por consiguiente es de esperar la siguiente hipótesis:

H2: En algunos modelos de bienestar existe una fuerte interdependencia entre mercado de trabajo y política social que permite combinar las políticas de mercado de trabajo con políticas redistributivas (como es posiblemente el caso del trabajo a tiempo parcial en los países escandinavos); en otros modelos de bienestar y con mercados laborales más segmentados el grado de interdependencia es más laxo o no están articuladas dichas politicas.

\subsubsection{Cultura del "compromiso igualitario" y modelos de bienestar}

La reacción de las personas ante la desigualdad que genera el mercado de trabajo tiende a consistir en reclamar la intervención del Estado, aunque inmediatamente hay que señalar que esta reclamación depende también del entorno cultural y de la tradición política. En efecto, dicha reacción está asociada a la cultura política, a la existencia de valores como el "compromiso igualitario" (Schwartz, 2007) muy extendido en la cultura política europea, especialmente relevante en los países agrupados en torno al modelo social-demócrata, aunque también en otras tradiciones políticas socialistas, social-cristiana o en la tradición "estatalista" francesa (Crouch, 2014).

Por contraste, en los países de tradición liberal la demanda de intervención del Estado para corregir las desigualdades parece menor. Hipotéticamente es de esperar que los países con mayor desigualdad (índice de Gini) sean los que dan más soporte a la demanda de intervención del gobierno para reducir las diferencias en los ingresos económicos y vice-versa.

No obstante, esta última hipótesis ha sido refutada en algunos hallazgos de estudios recientes y con datos empíricos que demuestran una débil relación lineal entre desigualdad en los ingresos (índice de Gini) y demanda de redistribución. En efecto, en los países de tradición liberal, como Estados Unidos y Reino Unido, la alta desigualdad en los ingresos económicos no está asociado a la demanda de redistribución (Kenworthy y Pontusson 2005; Dallinger, 2010). La explicación es que los ingresos económicos se relacionan con el valor del trabajo, el mérito y la contribución de los individuos y por tanto las diferencias en los ingresos adquieren carta de legitimidad (van Osorschot, 2008).

\subsection{Factores individuales}

Algunos estudios ya han puesto de relieve que aquellas personas que tienen alto nivel de estudios, altas cualificaciones, perciben ingresos económicos altos y tienen una alta posición social tienen menos probabilidades de tener actitudes pro-redistributivas (Wren y Rehm, 2014). Por el contrario, es de esperar que aquellas otras personas que tienen niveles de estudios bajos, empleo precarios, a tiempo parcial, contratos temporales o están en desempleo tengan actitudes pro-redistributivas (Martín Artiles, 
Molina y Carrasquer, 2016). Un aspecto de particular interés (y probable diferencia entre países) es el género y el trabajo a tiempo parcial. La política de empleo a tiempo parcial "marginal" (Klammer, 2000: 574), impulsada desde finales de los años noventa y destinada a la activación y movilización de mujeres desempleadas de larga duración, quizás esté hoy dando lugar a una creciente demanda de redistribución como consecuencia de los recortes en las políticas sociales.

Hipótesis 3.

Por consiguiente esperamos:

H3: Que probablemente las mujeres tienen una valoración distinta a los hombres en la demanda de redistribución, lo que factiblemente esté asociado a su mayor participación en el trabajo a tiempo parcial y a otras formas de empleo atípicas.

\section{Metodología}

La Encuesta Social Europa (ESE, 2012), ofrece información sobre diversos países europeos, de los cuales hemos seleccionado a 17 países que representan toda la gama de los modelos teóricos de bienestar que suele ser un punto de partida habitual en los estudios comparados. El limitado número de casos de países nos obliga a tomar ciertas cautelas con la interpretación de los datos. No obstante, los datos referidos a las opiniones de los individuos son importantes. La muestra recoge información aportada por 33.357 individuos encuestados, ${ }^{2}$ que responden a las preguntas relacionadas con las actitudes hacia la solidaridad, la redistribución y la percepción subjetiva de incertidumbre en los ingresos. Asimismo, Eurostat proporciona información estadística sobre las variables contextuales que explicitaremos más adelante.

\subsection{Variable dependiente}

La variable dependiente que usamos nos la proporciona la ESE, “¿Debería el gobierno reducir las desigualdades en los ingresos económicos?". Este es el indicador que hemos utilizado para analizar la demanda de políticas redistributivas. Dicha variable expresa una forma de intervención del gobierno para corregir las desigualdades, a la vez que capta la predisposición hacia la redistribución de los ingresos económicos mediante una escala de 1 a 5 , donde 1 equivale a una baja predisposición hacia la igualdad y 5 a mucha predisposición hacia la igualdad (véase otros estudios similares utilizando la misma metodología en Larsen, 2008; Karp et al., 2003; Wren y Rehm, 2014).

\subsubsection{Variables independientes}

Utilizamos un procedimiento de análisis multivariado y multinivel porque tratamos de captar la influencia de las tres mencionadas dimensiones apuntadas atrás. La influencia del 1) modelo de mercado laboral; 2) del modelo de bienestar y 3) de las características de los individuos sobre la formación de la opinión pública en relación a la redistribución. Las variables independientes han sido depuradas mediante el método

\footnotetext{
${ }^{2}$ En cada país siempre se ha entrevistado a más de 1.500 personas.
} 
de regresión logística "hacia atrás" (backward) que permite eliminar las variables no significativas en sucesivos pasos.

Las variables significativas utilizadas se corresponden con las tres dimensiones mencionadas:

1) En relación al modelo de mercado de trabajo, hemos utilizado la tasa de empleo público, la tasa de desempleo; la tasa de contratos temporales; la tasa de empleo a tiempo parcial y el índice de Gini;

2) en relación al modelo de bienestar, el porcentaje de gasto social en relación al PIB; el gasto en pensiones; el porcentaje de personas que perciben cualquier tipo de pensión; la pensión por desempleo y el PIB per cápita en poder de paridad de compra;

3) y, en relación a las variables individuales, hemos considerado el sexo, nivel de estudios, edad, la percepción subjetiva de incertidumbre en los ingresos económicos y la percepción de la posición social de los individuos.

Las variables eliminadas del modelo (mediante el método "hacia atrás") por no ser estadísticamente significativas son: 1) en relación al modelo de mercado de trabajo: la tasa de trabajadores autónomos; la tasa de empleo en empresas privadas; 2) en relación al modelo de bienestar: la tasa fiscal sobre ingresos; el riesgo de pobreza de las mujeres y la tasa de pobreza; 3) en relación a las variables individuales no se ha eliminado ninguna.

\subsection{Justificación de la elección de las variables}

En el primer grupo de variables referidas al mercado de trabajo, el índice de Gini sobre los ingresos salariales es una variable que nos permite observar las desigualdades entre los ingresos de la población de cada país. La desigualdad y la pobreza son dos hechos sociales muy visibles y asociados a la demanda de redistribución, lo que justifica su inclusión en este análisis. Es de esperar que aquellos países que registran mayor desigualdad sean los que precisamente demandan en mayor medida redistribución de los ingresos económicos. Asimismo, la tasa de desempleo parece tener una importante influencia en la demanda de reducción de las desigualdades en los ingresos económicos (Dallinger, 2010; Schmidt-Catran, 2014).

La tasa de "trabajadores pobres" (working poor), se refiere a aquellas personas que, aun teniendo empleo, sus ingresos son inferiores a la media de los ingresos del país. Esta variable puede ilustrar el grado de precarización del empleo en el país, a la vez que la demanda al gobierno para reducir las desigualdades en los ingresos económicos.

A modo de contraste también analizamos las diferencias en las actitudes hacia la redistribución entre aquellos que tienen empleo público y empleo en el sector privado. La tasa de empleo público puede constituir un factor importante para explicar las actitudes hacia la redistribución, así como el poder de los sindicatos e incluso su influencia positiva en el gasto en protección social y en otras variables correctoras de las desigualdades sociales (Kjelberg, 2009; Jensen, 2012)

El segundo grupo lo conforman aquéllas que están relacionadas con el Estado del Bienestar. El gasto en protección social, el gasto en pensiones y el riesgo de pobreza de 
un país son otras variables habitualmente utilizadas en los estudios comparativos, lo que nos puede permitir ver las diferencias de la opinión pública hacia la redistribución de acuerdo a distintos modelos de estados del Bienestar (Larsen, 2008; Dallinguer, 2010). El PIB per cápita y la tasa de imposición fiscal sobre los ingresos serían dos variables que nos podrían prestar apoyo explicativo sobre las diferencias entre los modelos de bienestar y las actitudes hacia la redistribución.

El tercer grupo, como variables de control, sintetiza las características de los individuos, tales como el sexo, la edad, el nivel de estudios, la percepción subjetiva de los ingresos y su auto-posicionamiento en la estructura social. Se espera que las personas con bajo nivel de estudios, percepción de incertidumbre en los ingresos y situadas en posiciones sociales bajas, demanden más políticas redistributivas. Por el contrario, aquellas personas con alto nivel de estudios y una percepción confortable de sus ingresos económicos serían menos favorables a las políticas redistributivas (Wren y Rehm, 2014).

\section{Resultados}

\subsection{Análisis descriptivo y variaciones}

Durante el periodo de crisis económica ha crecido la demanda de políticas redistributivas de los ingresos a los gobiernos nacionales como consecuencia del aumento de la incertidumbre económica. La demanda de políticas redistributivas ha pasado de una media de 3,62 (índice 100) en 2006 a 3,93 (índice 110) en una escala de 1 a 5 (donde 1 es poca demanda y 5 es mucha demanda de redistribución). La percepción de incertidumbre en los ingresos económicos es un elemento central para la demanda de políticas pro-redistributivas para corregir las desigualdades en los ingresos. Los países donde los ciudadanos perciben mayor incertidumbre en los ingresos son los países del Este y sur de Europa, como Bulgaria, Portugal, Estonia, República Checa, Eslovaquia, República Checa, Portugal Polonia y España, que son países de bajos salarios, empleo precario, alto desempleo y bajo nivel de empleo público (véase tabla 1).

El saldo negativo entre el índice de percepción de incertidumbre (tomando como referencia un índice 100 a partir de la media de los 17 países para el año 2006) y demanda de redistribución, nos muestra la demanda más acuciante de políticas correctoras de la incertidumbre en determinados países: Bulgaria, Portugal, Eslovaquia, Estonia, Polonia, España, Eslovenia, Irlanda y República Checa (véase gráfico 1). Estos países han visto incrementar la demanda de políticas solidarias de redistribución entre 2006 y 2012 porque la incertidumbre en los ingresos ha aumentado en dicho periodo.

Por el contrario, los ciudadanos de los países que conforman el Sistema Gante (Bélgica, Suecia, Dinamarca, Noruega y Finlandia) tienen un saldo positivo entre percepción de incertidumbre y demanda de redistribución, a los que hay que añadir Alemania, Holanda y Reino Unido. Es decir, en estos países los ciudadanos han percibido, entre 2006 y 2012, sus ingresos como más seguros y por ello no han tenido un crecimiento de la demanda de redistribución. 
Tabla 1: Percepción incertidumbre / certidumbre y demanda de redistribución ingresos económicos

\begin{tabular}{|c|c|c|c|c|c|c|c|}
\hline & \multicolumn{7}{|l|}{ I } \\
\hline & & $\mathrm{N}$ & 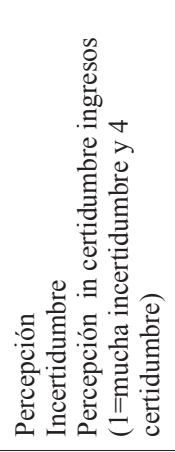 & 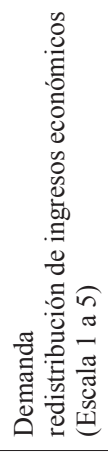 & 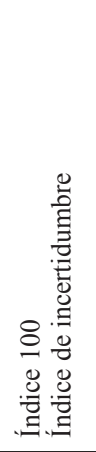 & 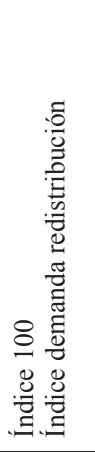 & 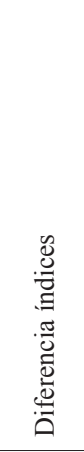 \\
\hline \multirow{9}{*}{ 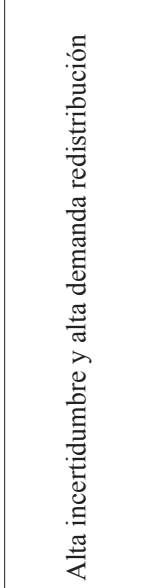 } & Bulgaria & 2226 & 1,82 & 4,33 & 62,12 & 110,18 & $-48,06$ \\
\hline & Portugal & 2133 & 2,4 & 4,4 & 81,91 & 111,96 & $-30,05$ \\
\hline & Eslovaquia & 1828 & 2,48 & 3,94 & 84,64 & 100,25 & $-15,61$ \\
\hline & Estonia & 2348 & 2,62 & 4,06 & 89,42 & 103,31 & $-13,89$ \\
\hline & Polonia & 1865 & 2,73 & 4,03 & 93,17 & 102,54 & $-9,37$ \\
\hline & España & 1825 & 2,85 & 4,11 & 97,27 & 104,58 & $-7,31$ \\
\hline & Republica Checa & 1900 & 2,6 & 3,71 & 88,74 & 94,4 & $-5,66$ \\
\hline & Irlanda & 2544 & 2,8 & 3,97 & 95,56 & 101,02 & $-5,45$ \\
\hline & Eslovenia & 1228 & 3,08 & 4,25 & 105,12 & 108,14 & $-3,02$ \\
\hline \multirow{4}{*}{ 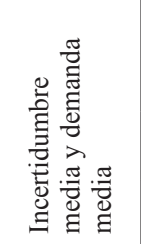 } & Suecia & 1821 & 3,38 & 3,82 & 115,36 & 97,2 & 18,16 \\
\hline & Reino Unido & 2216 & 3,14 & 3,63 & 107,17 & 92,37 & 14,8 \\
\hline & Alemania & 2942 & 3,16 & 3,84 & 107,85 & 97,71 & 10,14 \\
\hline & Finlandia & 2173 & 3,08 & 3,95 & 105,12 & 100,51 & 4,61 \\
\hline \multirow{4}{*}{ 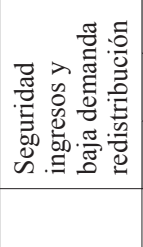 } & Noruega & 1617 & 3,51 & 3,49 & 119,8 & 88,8 & 30,99 \\
\hline & Dinamarca & 1599 & 3,61 & 3,02 & 123,21 & 76,84 & 46,36 \\
\hline & Holanda & 1836 & 3,31 & 3,39 & 112,97 & 86,26 & 26,71 \\
\hline & Total & 33357 & 2,93 & 3,93 & 100 & 100 & 0 \\
\hline
\end{tabular}

Fuente: Elaboración propia con datos ESS (2012). 
Gráfico 1: Saldo percepción alta incertidumbre y demanda redistribución

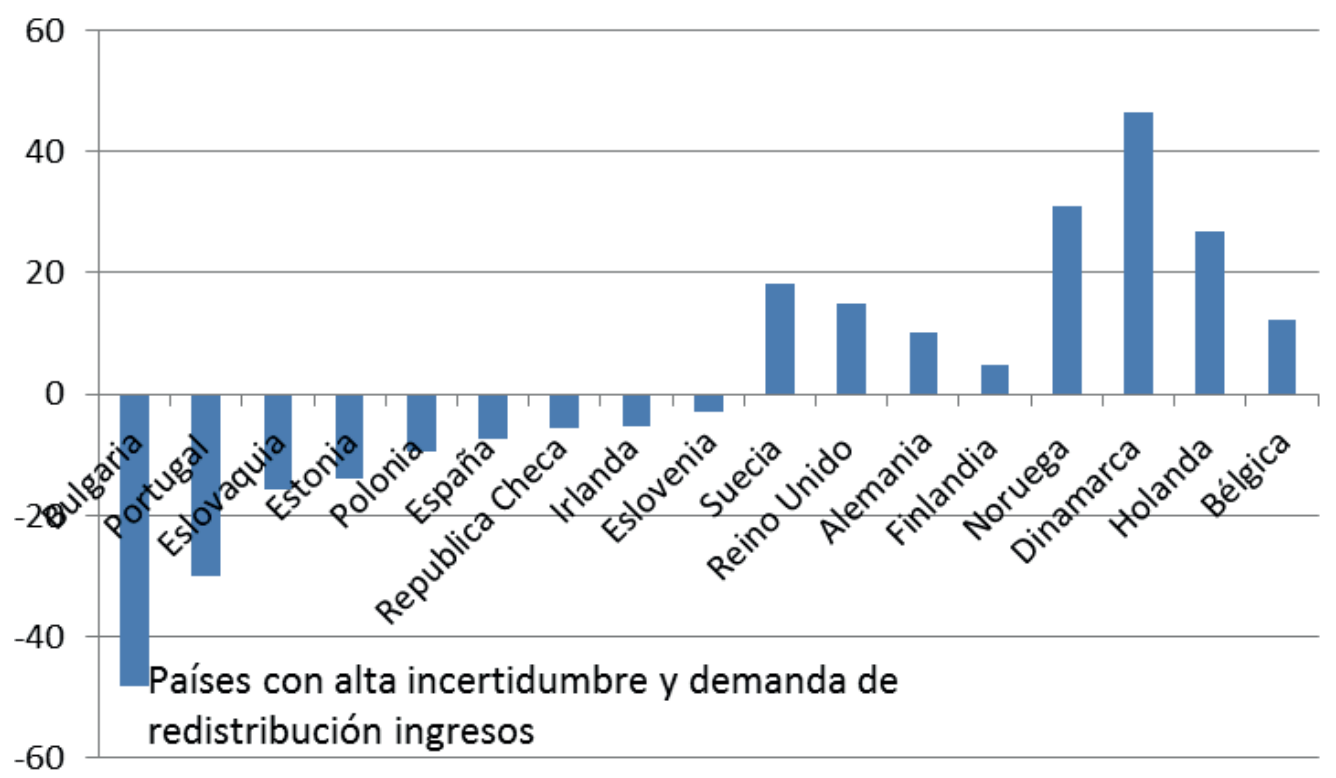

Fuente: Elaboración propia con datos ESS (2012).

\subsection{Análisis de clasificación}

El análisis más detallado del gráfico anterior nos los proporciona el siguiente análisis de correspondencias múltiples (ACM), que nos permite clasificar y ordenar espacialmente la distribución de las variables contextuales sobre dos ejes o dimensiones, de modo que se puede observar la posición respecto al centro (posición media de todas las variables) y, por tanto, ello nos permite captar la distancia, la proximidad, el modo de estructuración y clasificación de los países en relación a las actitudes hacia la redistribución.

El conjunto de variables explicadas tiene una varianza del $68 \%$, lo que se puede considerar como óptima. Las variables que tienen más peso discriminante respecto al centro (que tiene un valor de referencia igual a 0 ) son, por este orden, el nivel de riqueza per cápita (véase gráfico 2), que influye en la capacidad de redistribución del país; el gasto en pensiones; el nivel de desempleo, el contrato temporal, los working poor, el nivel de desigualdad (índice de Gini) y el empleo público. Estas son las variables que explican la distribución espacial (gráfico 3) y más estrechamente asociadas a la demanda de redistribución de los ingresos.

El análisis (ACM) de clasificación (gráfico 3) proporciona un mapa de la distribución espacial de la incertidumbre y de las actitudes pro-redistributivas en Europa en el cual se pueden distinguir cinco grupos clasificados en dos dimensiones. 
- La primera dimensión (D1) explica el 70\% de la varianza, que se define por la dimensión horizontal (D1) desempleo y empleo temporal versus empleo estable en el sector público. Este gráfico nos muestra una polarización de las actitudes proredistributivas de determinados países -Sur y Este de Europa- en la parte superior del gráfico y otro grupo de países - escandinavos y germánicos- en la parte inferior del gráfico.

- En la segunda dimensión (D2) la varianza explicada es del 66\% y se define por la dimensión vertical baja versus alta demanda de redistribución de ingresos económicos.

Gráfico 2: Variables discriminantes en la clasificación

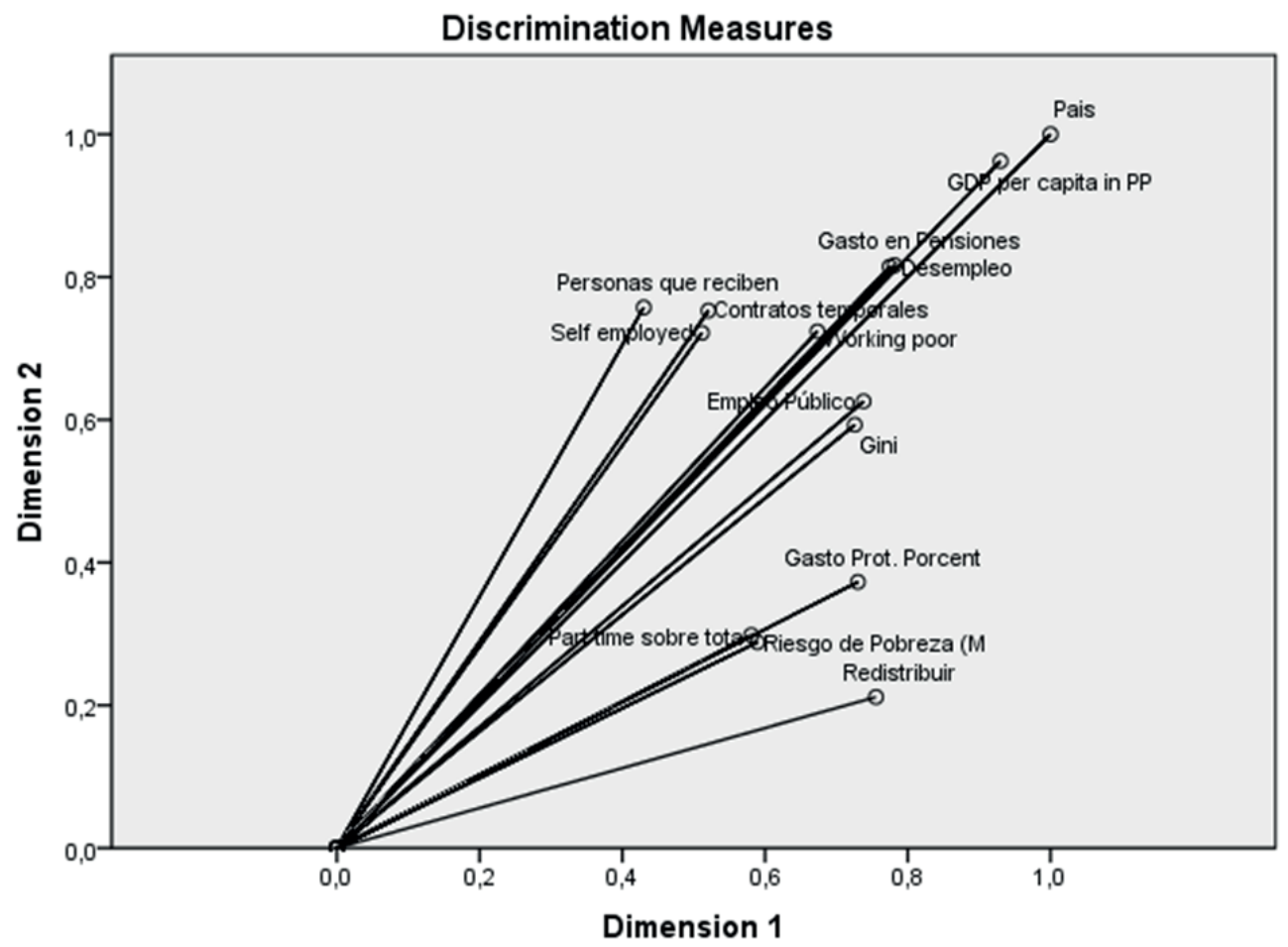

Symmetrical Normalization.

Fuente: Elaboración propia con datos ESS (2012).

1. Modelo Neoliberal del Este de Europa. En el primer cuadrante se ubican los países del Este de Europa (Estonia, Polonia, Eslovaquia, Bulgaria). Las principales características de este grupo son: un índice de desigualdad (Gini) igual o superior a la media; un riesgo de pobreza también muy cercano o incluso superior a la media; un nivel de gasto en 
protección social inferior a la media; un nivel de gasto en pensiones ligeramente inferior a la media; un PIB per cápita claramente inferior a la media, así como una tasa fiscal sobre ingresos también inferior a la media. Este grupo de países post-comunistas tiene una tasa de empleo público superior a la media, pero salarios bajos. Polonia y Eslovenia tienen una tasa de empleo temporal superior a la media. Pero los cuatro países tienen una tasa de empleo a tiempo parcial inferior a la media y la tasa de desempleo es cercana a la media del conjunto de los 17 países. La incertidumbre en los ingresos y la demanda de políticas pro-redistributivas es también superior a la media. Son países con débil poder sindical y un sistema de negociación colectiva descentralizada que dificulta la negociación de la política macro-económica y por consiguiente la influencia del poder sindical en la redistribución. Estos países han desmantelado a los antiguos sindicatos y han llevado a cabo duras políticas de privatización de las empresas públicas y de las cooperativas agrarias (Borisov y Clarke, 2006).

Gráfico 3: Distribución espacial, incertidumbre y redistribución

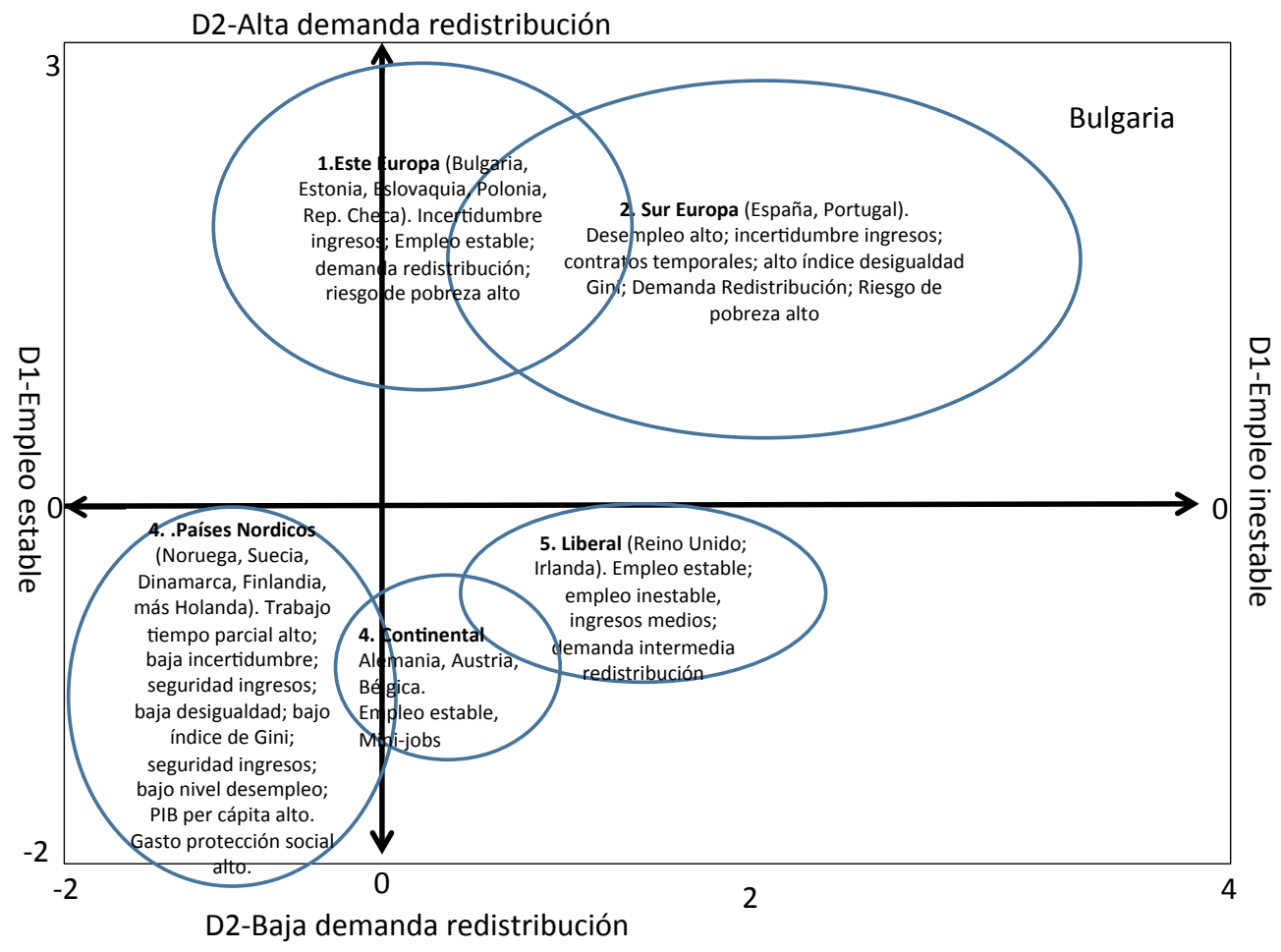

Fuente: Elaboración propia con datos ESS (2012). 
2. Modelo Liberal Mediterráneo. En el segundo cuadrante, situado también por encima de la dimensión 1, sitúa en el lado de la derecha aquellos países que tienen aún más precariedad en el empleo: España y Portugal. La precariedad en el empleo debilita el poder de negociación sindical. Ambos países tienen un desempleo de larga duración mayor que el anterior grupo, lo que está asociado a la demanda de subsidios y políticas redistributivas (Keller y Seifert, 2013).

Los países del Sur y Este de Europa parecen converger en la orientación liberal con el modelo anglosajón, son demandantes de políticas pro-redistributivas, tienen un sistema de negociación colectiva tendente a la descentralización y conforman lo que Banyuls et al. (2009) denominan modelo "neoliberal del mediterráneo". Sus principales características son un alto volumen de empleo precario, como es particularmente el contrato temporal y una alta participación en la figura de los "working poor", lo que significa empleo de bajos salarios en el umbral de la pobreza. El empleo emergente es un factor de incertidumbre. España y Portugal tienen menos volumen de empleo público que los países del Este; sus tasas de empleo a tiempo parcial son inferiores a la media. El PIB per cápita es también inferior a la media, así como la tasa de imposición fiscal.

Al igual que en los países del Este, los ciudadanos perciben una incertidumbre en sus ingresos económicos superior a la media, lo que concuerda también con el hecho de que demanden políticas pro-redistributivas. De hecho España es el país que registra mayor desigualdad en el índice de Gini (35\%), seguido de Portugal (34,5\%). Es más, España es uno de los países donde más han crecido las desigualdades entre 2006 y 2012: un 3,1\%, como se refleja en su ubicación en el gráfico anterior. Los países del Sur de Europa muestran una relación lineal entre el aumento del trabajo a tiempo parcial y el aumento de la demanda de redistribución (r,724), así como el aumento del riesgo de pobreza $(r, 765)$. O sea, reflejan una inadecuada articulación entre políticas de empleo a tiempo parcial, políticas sociales y políticas de conciliación entre la vida laboral y familiar (Carrasquer y Martín Artiles, 2005).

3. Modelo nórdico. En el tercer cuadrante figuran los países escandinavos (Noruega, Dinamarca y Suecia) más Holanda, que comparten entre sí empleo estable y baja demanda de redistribución. Estos países tienen un volumen de empleo público más alto (en sanidad, educación y administración pública), lo que proporciona equidad, empleo de calidad y favorecen la formación de un círculo virtuoso: mayor afiliación y poder sindical, así como un Estado del Bienestar más generoso derivado del poder de negociación de los sindicatos (Esping Andersen, 2000; Cho, 2014). Como dice Larsen (2008) son los países con tradición política social-demócratas con "pasión por la igualdad". A ello hay añadir el papel que ha venido jugando las políticas de igualdad de género en los países escandinavos, lo que ha sido importante para reducir las desigualdades en los ingresos (Esping-Andersen, 2014).

Un aspecto de interés especial es que estos países tienen también un alto volumen de empleo a tiempo parcial voluntario y ubicado en el sector público, lo que facilita la 
conciliación entre la vida laboral y familiar, al tiempo que no genera riesgo de pobreza (Jepsen, 2000; Campillo, 2010).

Por otra parte, los países nórdicos son los que presentan menos desigualdad; en el índice de Gini, están bastante por debajo de la media: incluso entre 2006 y 2012 se han reducido aún más las desigualdades en Noruega (-6\%), y en Holanda (-1\%). Finlandia ha permanecido igual, pero Dinamarca ha incrementado la desigualdad en un $4 \%$ más. Un contraste respecto a los países del Sur de Europa es que el trabajo a tiempo parcial tiene una correlación negativa con la demanda de redistribución $(\mathrm{r}-, 455)$, así como con el riesgo de pobreza (r-, 558), justo lo contrario a lo que ocurre en España y Portugal.

En los países nórdicos la seguridad que proporciona el empleo a tiempo parcial está relacionada con un alto volumen de empleo público, además de un potente sistema de protección social (Jepsen, 2000: 681-682). En estos países la demanda de políticas proredistributivas es inferior a la media porque los ingresos económicos son percibidos de forma segura y confortable por los ciudadanos. No en vano el gasto en protección social es superior a la media, como también lo es la tasa de imposición fiscal sobre los ingresos económicos y el PIB per cápita.

Gráfico 4: Empleo público y gasto en protección social

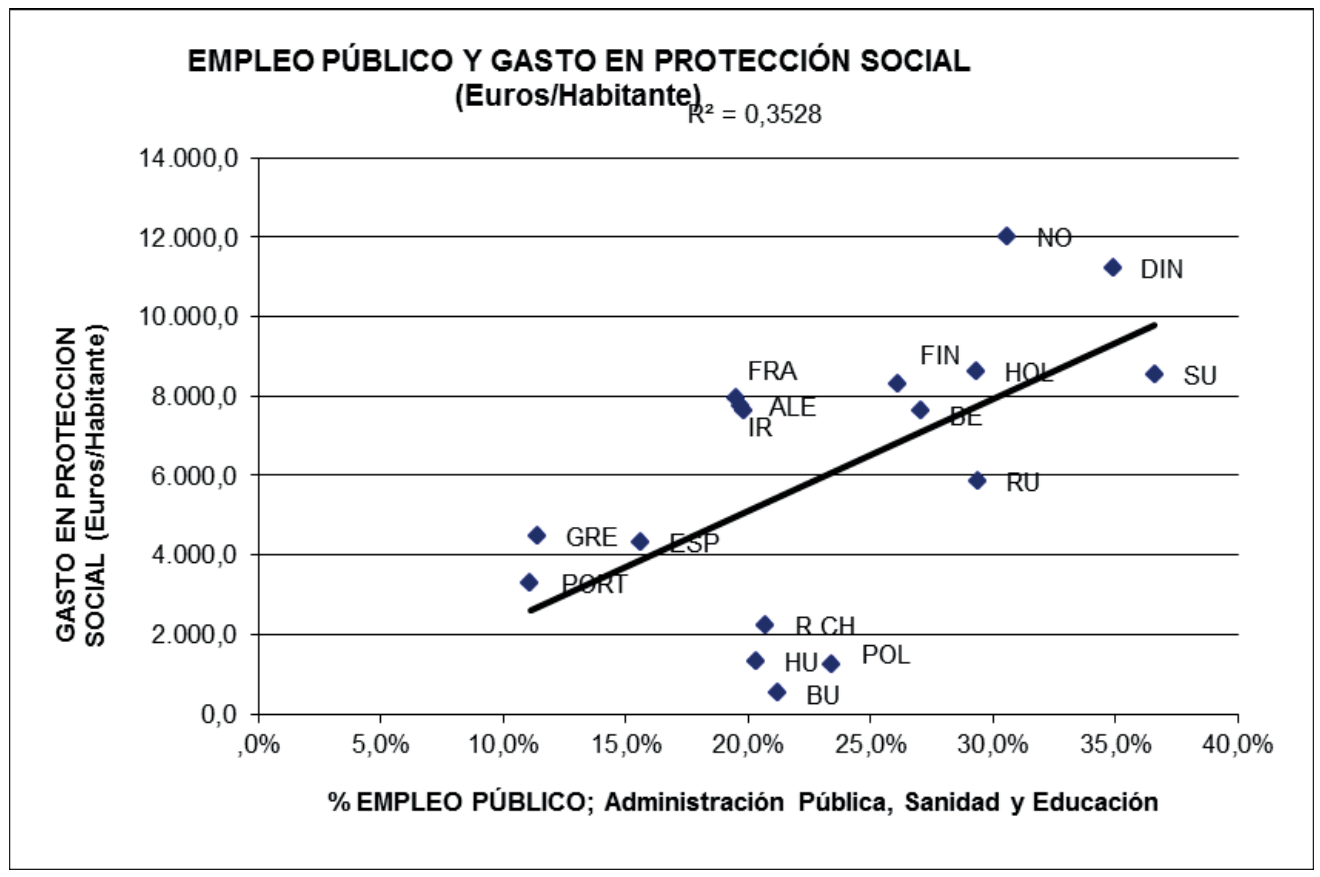

Fuente: Elaboración propia con datos ESS (2012). 
4. Modelo Continental. Un poco más alejados se encuentran otros países del modelo de bienestar continental, como Alemania, Austria y Bélgica, que comparten una cierta estabilidad en el empleo, aunque también con empleos precarios (mini-jobs) y mediabaja demanda de redistribución. Presentan un índice de Gini inferior a la media, pero la desigualdad ha creciendo en algunos de ellos entre 2006 y 2012: por ejemplo en Alemania un 1,5\%. Y tienen un volumen de empleo público cercano a la media o bien ligeramente superior. Alemania, Austria y Bélgica tienen un volumen de empleo a tiempo parcial superior a la media, pero sin que ello comporte tanta desigualdad social como en el caso británico porque en estos países el empleo a parcial cuenta con ayudas a las familias, al transporte y la vivienda. Es decir, reflejan una forma de articulación entre políticas de empleo y políticas sociales.

5. Modelo Liberal. En el cuarto cuadrante se ubican Reino Unido e Irlanda, colindantes con ciertas características de empleo precario que tienen los países del Este y Sur de Europa. El Reino Unido tiene un PIB per cápita superior a la media, así como un gasto en protección social ligeramente superior a la media, pero también con un volumen de working poor superior, lo que connota una fuerte diferenciación social, como se plasma en un índice de Gini superior a la media. La desigualdad en el Reino Unido (índice Gini $32,5 \%)$ no sólo es superior a la media, sino que incluso ha crecido ligeramente $(+0,3 \%)$ entre 2006 y 2012, pero la demanda de redistribución es menos importante porque la desigualdad es más aceptada socialmente aquí que en otros países (Dallinger, 2010).

\subsection{Factores determinantes en la incertidumbre}

El análisis de regresión nos permite identificar el peso de las variables individuales y contextuales más influyentes en la percepción de incertidumbre económica (tabla 2). En nuestro modelo hemos introducido los tres tipos de variables mencionadas atrás: de control individual, de bienestar y de mercado de trabajo explicitadas en el apartado metodológico. A través del método de análisis de regresión "hacia atrás" (backward) se han ido descartando gradualmente, en sucesivos pasos, las menos significativas o aquellas otras que mostraban colinealidad, de modo que en el quinto paso de la regresión ha quedado un reducido grupo de variables.

La varianza explicada es del 45,9\%. Las variables que influyen en la percepción de incertidumbre se presentan en dos modelos. En el modelo 1 la variable de más peso es el lugar que se ocupa en la sociedad: cuanta más alta es la posición social de los individuos menos percepción de incertidumbre en los ingresos y por tanto también menor peso tiene la actitud redistributiva para dicho grupo social, lo que coincide con la hipótesis esperada. La siguiente variable de influencia es el nivel de estudios: cuanto más alto es el nivel de estudios menos es la incertidumbre en los ingresos económicos y, por tanto, igualmente menor peso tienen las actitudes favorables hacia la redistribución. En tercer lugar el sexo es la siguiente variable con más peso determinante en la incertidumbre: las mujeres perciben más la incertidumbre en los ingresos económicos que los hombres, lo que probablemente se asocia a que las primeras ocupan empleos más precarios y con menor nivel de remuneración salarial que los hombres, lo que concuerda con lo 
hallado por Jepsen (2000). Por consiguiente, no debe sorprender que las mujeres tengan actitudes más pro-redistributivas que los hombres, porque, además, participan más del empleo a tiempo parcial, lo que implica menos ingresos. La edad no es significativa estadísticamente y de hecho desaparece en el segundo modelo cuando se añaden las variables contextuales al modelo de análisis.

Tabla 2: Factores contextuales de mercado de trabajo y bienestar

\begin{tabular}{|c|c|c|c|c|c|c|c|c|c|c|c|c|c|c|}
\hline & & Mercado de tra & abajo & & & & Politica redist & tributiva & & & & & & \\
\hline Paises & $\begin{array}{l}\text { Empleo } \\
\text { Público } \\
\end{array}$ & Contratos tem & \begin{tabular}{|c|}
$\%$ \\
trabajadores \\
autónomos \\
\end{tabular} & \% tiempo pard & $\begin{array}{l}\text { Working } \\
\text { poor }\end{array}$ & îndice de Gini & Riesgo de Pob & Gasto Prot. Pd & Gasto en Pens & PIB per capita & Impuesto & Diferencias $d d$ & Pensión por d & Desempleo lar \\
\hline Belgica & 0,3 & 8,1 & 0,1 & 25,1 & 4,6 & 26,6 & 15,3 & 30,4 & 12,4 & 120,0 & 16,4 & $-0,5$ & 989,8 & 3,4 \\
\hline \begin{tabular}{|l|} 
Bulgaria \\
\end{tabular} & 0,4 & 4,5 & 0,1 & 2,4 & 7,4 & 33,6 & 21,2 & 17,7 & 8,7 & 47,0 & 4,9 & $-30,9$ & 8,3 & 6,8 \\
\hline Rep. Checa & 0,3 & 8,8 & 0,1 & 5,8 & 4,5 & 24,9 & 9,6 & 20,4 & 9,7 & 81,0 & 7,2 & $-9,6$ & 65,0 & 3,0 \\
\hline Alemania & 0,3 & 8,5 & 0,1 & 25,7 & 7,8 & 28,3 & 16,1 & 29,4 & 12,3 & 126,0 & 12,0 & $-0,5$ & 964,6 & 2,1 \\
\hline Dinamarca & 0,4 & 13,9 & 0,1 & 26,7 & 5,6 & 28,1 & 13,1 & 34,2 & 14,3 & 123,0 & 30,4 & $-3,0$ & 567,1 & 2,5 \\
\hline Estonia & 0,4 & 3,7 & 0,0 & 10,5 & 8,3 & 32,5 & 17,5 & 16,1 & 11,4 & 71,0 & 6,8 & 2,0 & 13,5 & 5,5 \\
\hline España & 0,2 & 23,4 & 0,1 & 14,5 & 12,3 & 35,0 & 22,2 & 26,1 & 7,1 & 96,0 & 10,3 & $-12,8$ & 451,9 & 11,0 \\
\hline Finlandia & 0,4 & 15,6 & 0,1 & 15,1 & 3,8 & 25,9 & 13,2 & 30,0 & 12,5 & 115,0 & 16,0 & $-7,9$ & 718,3 & 1,6 \\
\hline Reino Unido & 0,3 & 6,3 & 0,1 & 27,2 & 9,0 & 32,8 & 16,0 & 27,3 & 11,8 & 104,0 & 15,0 & $-3,3$ & 205,8 & 2,7 \\
\hline Irlanda & 0,3 & 10,2 & 0,1 & 24,0 & 5,4 & 29,9 & 15,7 & 29,6 & 8,9 & 129,0 & 12,6 & 0,1 & 492,4 & 9,1 \\
\hline \begin{tabular}{|l} 
Holanda \\
\end{tabular} & 0,3 & 19,5 & 0,1 & 49,8 & 4,6 & 25,4 & 10,1 & 32,3 & 13,0 & 127,0 & 10,9 & 1,2 & 499,4 & 1,8 \\
\hline \begin{tabular}{|l|} 
Noruega \\
\end{tabular} & 0,4 & 8,4 & 0,1 & 26,4 & 5,0 & 22,6 & 10,0 & 29,2 & 8,5 & 191,0 & 21,1 & $-16,0$ & 329,0 & 0,6 \\
\hline Polonia & 0,4 & 26,9 & 0,2 & 7,9 & 10,4 & 30,9 & 17,1 & 19,2 & 11,6 & 67,0 & 7,2 & $-6,3$ & 40,5 & 4,1 \\
\hline \begin{tabular}{|l} 
Portugal \\
\end{tabular} & 0,2 & 22,0 & 0,1 & 14,6 & 9,9 & 34,5 & 17,9 & 26,5 & 14,8 & 76,0 & 9,3 & $-0,9$ & 195,4 & 7,7 \\
\hline Suecia & 0,4 & 16,4 & 0,1 & 26,5 & 6,7 & 24,8 & 14,1 & 29,6 & 11,6 & 126,0 & 18,1 & $-14,5$ & 610,4 & 1,5 \\
\hline Eslovenia & 0,5 & 17,1 & 0,1 & 9,8 & 6,5 & 23,7 & 13,5 & 25,0 & 11,4 & 84,0 & 7,7 & $-10,7$ & 105,7 & 4,3 \\
\hline Eslovaquia & 0,4 & 6,8 & 0,1 & 4,1 & 6,2 & 25,3 & 13,2 & 18,2 & 8,3 & 76,0 & 5,6 & 0,2 & 39,3 & 9,4 \\
\hline Total & 33,2 & 12,9 & 9,1 & 18,6 & 6,9 & 28,5 & 15,0 & 26,0 & 11,1 & 103,5 & 12,4 & $-6,7$ & 370,4 & 4,5 \\
\hline
\end{tabular}

Fuente: Elaboración propia con datos Eurostat 2012.

En el modelo 2, las anteriores variables individuales no sufren modificaciones, pero pierden peso explicativo en relación a otras de tipo contextual. En este sentido, la variable de mayor peso es el "número de personas que reciben cualquier tipo de pensión" contribuye a corregir la incertidumbre. Dicha variable tiene una relación negativa: cuanto mayor es el número de personas que perciben una prestación o un subsidio del Estado, menos incertidumbre tienen estas. La segunda variable explicativa de la incertidumbre es el trabajo a tiempo parcial, aunque dicha variable se comporta de forma diferente en los países nórdicos y en los países del Sur y Este de Europa (Esping-Andersen, 2000). La cuantía de la pensión por desempleo es otra variable que influye en la incertidumbre en los ingresos. Y el nivel de riqueza per cápita se vuelve a confirmar como una variable determinante en la percepción de incertidumbre, tal como sostienen Mau et al. (2012) que demuestran la importancia del crecimiento económico para la provisión de bienestar.

\subsection{Factores determinantes de la demanda de redistribución}

En relación a las actitudes pro-redistributivas el mismo tipo de regresión nos muestra que las variables relacionadas con el Estado de Bienestar tienen una varianza explicativa menor $(33,3 \%)$ que las variables relacionadas con el mercado de trabajo. Las variables 
más importantes son el gasto en pensiones, seguida del riesgo de pobreza, porcentaje de gasto en protección social, la tasa de desempleo, autoempleo y la percepción de incertidumbre en los ingresos, lo que explicaremos con más detalle a continuación (tabla 3).

Tabla 3: Variables asociadas a la demanda de redistribución

\begin{tabular}{|l|c|c|l|c|c|}
\hline Mercado trabajo & \multicolumn{2}{|c|}{ Redistribución } & \multicolumn{2}{c|}{ Estado Bienestar } & \multicolumn{2}{c|}{ Redistribución } \\
\hline Variable & r Pearson & Sig & Variable & r Pearson & Sig \\
\hline Empleo público &,- 076 & $\mathrm{~ns}$ & Desigualdad Gini &, 444 & $\mathrm{~ns}$ \\
\hline Empresa privada &,- 150 & $\mathrm{~ns}$ & Riesgo pobreza &, $632^{* *}$ & $* *$ \\
\hline Auto-empleo &, 355 & $\mathrm{~ns}$ & Gasto protección social &,$- 575^{*}$ & $*$ \\
\hline Desempleo &, $564 *$ & $*$ & Gasto en Pensiones &,- 237 & $\mathrm{~ns}$ \\
\hline $\begin{array}{l}\text { Desempleo } \\
\text { larga duración }\end{array}$ &, $585 *$ & $*$ & Pib per cápita &,$- 631^{* *}$ & $* *$ \\
\hline $\begin{array}{l}\text { Contratos } \\
\text { temporales }\end{array}$ &, 136 & $\mathrm{~ns}$ & $\begin{array}{l}\text { Personas que reciben } \\
\text { cualquier tipo de pensión o subsidio }\end{array}$ &, 338 & $\mathrm{~ns}$ \\
\hline $\begin{array}{l}\text { Trabajo } \\
\text { a tiempo parcial }\end{array}$ &,$- 653^{* *}$ & $* *$ & Tasa de impuesto sobre ingresos &,$- 750^{* *}$ & $* * *$ \\
\hline Working poors &, 470 & $*$ & $\begin{array}{l}\text { Diferencia de riesgo de pobreza } \\
\text { hombres / mujeres }\end{array}$ &,- 257 & $\mathrm{~ns}$ \\
\hline N & 17 & & Pensión por desempleo &,- 355 & $\mathrm{~ns}$ \\
\hline
\end{tabular}

Significación: *pq > ,050;**pq>,010;***pq>,001.

Fuente: ESE (2012) y variables externas de Eurostat (2012).

En primer lugar, las variables referidas a las características de las personas tienen un peso moderado en la explicación de las actitudes hacia la redistribución. La percepción de incertidumbre en los ingresos es la que más influye en la demanda de redistribución, seguida del sexo: las mujeres pesan más que los hombres, lo que se debe a que éstas tienen una mayor percepción de incertidumbre en sus ingresos y sus empleos son de peor calidad. Igualmente son más partidarios de las políticas redistributivas ciertos perfiles individuales, como son los hombres que han estado en situación de desempleo, 
aquellos que perciben su posición social en un estrato bajo y aquellos que tienen bajo nivel de estudios. Estos grupos sociales reclaman que el gobierno debe corregir las desigualdades, pero mediante el impulso de mecanismos de "cierre social" limitando el acceso a los inmigrantes, lo que es particularmente relevante en Hungría, Grecia y en el resto de los países de Europa del Este (Martín Artiles, Carrasquer y Molina, 2016).

Por el contrario, detectamos otros perfiles individuales orientados hacia el individualismo y la competencia. Como son aquellas personas que tienen estudios universitarios, que tienen actitudes menos favorables hacia la redistribución, lo que concuerda con otros hallazgos que ponen de relieve la actitud más individualista de los jóvenes y de aquellos que tienen estudios universitarios, en comparación con aquellas otras personas que tienen bajo nivel de estudios (Wren y Rehm, 2014). Las actitudes individualistas son más relevantes en el ámbito anglosajón, donde el pensamiento tradicionalmente dominante ha sido liberal.

Asimismo, las personas que consideran que su posición social es alta tienen menos probabilidades de tener actitudes pro-redistributivas que aquellas otras personas que consideran que su posición social es baja. Estas últimas son más favorables hacia la redistribución para mitigar la incertidumbre de sus ingresos económicos. Nótese, además, que cuando se combinan las variables individuales con las contextuales, las primeras pierden peso en su capacidad explicativa, sólo hay una que gana peso: la percepción de incertidumbre en los ingresos, lo que nos indica que los diferentes contextos contribuyen a generar incertidumbre o bien seguridad, como ya hemos visto con el trabajo a tiempo parcial y las diferencias entre los países escandinavos y del Sur y Este de Europa (Klammer, 2000). En otras palabras, las políticas de transferencias sociales, ayudas a los jóvenes y las familias juegan un papel importante para mitigar el empleo de bajos salarios, el empleo temporal y el empleo a tiempo parcial.

En segundo lugar, las variables relacionadas con la situación precaria en el mercado de trabajo contribuyen de forma importante a la demanda de redistribución. El desempleo es la variable de mayor peso, seguida del autoempleo, los contratos temporales y el trabajo a tiempo parcial. La precariedad en el empleo ha sido un fenómeno de creciente importancia en muchos países de la Unión Europa. Por consiguiente, como era de esperar, este conjunto de variables contribuye a la demanda de políticas redistributivas (Larsen, 2008).

Por último, las variables referidas a las políticas de bienestar tienen un mayor peso en la predicción de las actitudes. Son singularmente significativas variables como el gasto en pensiones, el porcentaje de gasto en protección social y el riesgo de pobreza. A ello hay que añadir que el riesgo de pobreza de las mujeres también tiene una notable influencia en la demanda de redistribución, lo que está asociado al hecho de que muchos empleos precarios, atípicos y de bajos salarios los desempeñan mujeres. En menor medida, otra variable influyente es el gasto en pensiones por desempleo. Estas variables están estrechamente relacionadas con la política redistributiva y la corrección de las desigualdades en los ingresos económicos. 


\section{Conclusiones}

No cabe duda que el nivel de riqueza per cápita tiene un papel determinante en la percepción de incertidumbre y en la demanda de redistribución de ingresos. Pero las diferencias en la demanda de políticas redistributivas entre países se generan en función del modelo de empleo, de modo que los países con menos empleo público y de calidad demandan una mayor redistribución de ingresos.

\subsection{Modelo de empleo}

En relación a la primera hipótesis (H1) hemos constatado que los principales predictores de incertidumbre en los ingresos son el desempleo, el trabajo a tiempo parcial, los contratos temporales y los bajos salarios. Pero también el propio empleo ya no es, por sí solo, un factor de integración social, como lo demuestran los "working poor": trabajadores con bajos salarios y riesgo de pobreza que demandan políticas redistributivas. La precariedad en el empleo y la incertidumbre se localizan en los países del Este y Sur de Europa, donde han aumentado de forma notable la precariedad en el empleo y las desigualdades en el mercado laboral durante el periodo 2006-2012. Estos países han tenido una alta tasa de desempleo, una fuerte crisis financiera y se han visto obligados a profundas reformas de los mercados de trabajo, con lo cual se ha debilitado la representación sindical y la negociación colectiva. En estos países, otro de los factores que contribuye a la demanda de políticas redistributivas es el bajo nivel de empleo público, lo que no genera ningún "círculo virtuoso". Precisamente Larsen (2008: 163) llama la atención en relación al riesgo político que se deriva de la percepción subjetiva de incertidumbre: la fragmentación y heterogeneidad del mercado de trabajo condiciona la percepción de solidaridad, la articulación de la representación sindical y la formación de coaliciones políticas para la sostenibilidad del bienestar.

Igualmente, en los países agrupados en el modelo neoliberal del Este de Europa, se aprecia una notable incertidumbre en los ingresos y una notable demanda de políticas pro-redistributivas en el mismo periodo 2006-2012. Estos son países que tienen un amplio abanico de empleo precario (a tiempo parcial, autónomos y contratos temporales). Los países del Sur y Este de Europa parecen converger en el deterioro de sus mercados de trabajo, en la pérdida de calidad del empleo y en la política de reformas hacia un sistema de negociación colectiva descentralizada, lo que se vincula con una orientación micro-económica acorde con la orientación neoliberal.

Caso aparte es el modelo liberal anglosajón: aunque la incertidumbre en los ingresos ha aumentado entre 2006 y 2012, ello no implica una demanda paralela de políticas de solidaridad redistributivas. Posiblemente la cultura del ámbito anglosajón tolera más las diferencias sociales. Este hallazgo coincide con lo observado por Dallinger (2010), que ya subrayó la existencia de una relación lineal débil entre incertidumbre en los ingresos y demanda de redistribución en las sociedades anglosajonas. En este país de tradición liberal es donde hay una mayor proporción de personas que valoran el mérito individual como requisito para acceder a los ingresos económicos altos. Por tanto la cultura del mérito individual amortigua la demanda de políticas solidarias redistributivas. Posiblemente esta cultura contribuye a que la política de contratación 
del empleo no esté estrechamente vinculada con la política social, como decíamos en la segunda hipótesis.

Los países nórdicos, con mayor volumen de empleo público, son los que ofrecen a sus empleados una mayor equidad y seguridad en los ingresos, estabilidad en el empleo y presentan menos requerimientos de políticas redistributivas. En dichos países el empleo público en educación, sanidad y administración pública genera un "círculo virtuoso" (Kjellberg, 2000) porque contribuye a la formación de un mayor poder sindical, con tasas de afiliación altas y fuerte capacidad de negociación colectiva, lo que a su vez favorece el desarrollo de políticas redistributivas a través de sistemas de negociación centralizados y articulados con la política macro-económica. Este "círculo virtuoso" se refleja en una mayor importancia de las pensiones por jubilación, en la cobertura de las pensiones y subsidios por desempleo, lo que contribuye a reducir la incertidumbre. A ello hay que añadir que se trata de países con empleos regulados y altos salarios, lo que también facilita una mayor imposición fiscal y por ende la implementación de políticas redistributivas.

\subsection{Modelo de Bienestar}

En relación a la segunda hipótesis (H2), el modo de combinación de estas políticas sociales con los ingresos del mercado de trabajo influye de distinta manera en la demanda de políticas redistributivas. Pero la incertidumbre en los ingresos está estrechamente relacionada con el nivel de riqueza del país y con el poder de los sindicatos y el modo de articulación de la negociación colectiva. Los países nórdicos cuentan con un sistema centralizado de negociación colectiva que contribuye a reducir la dispersión de los ingresos salariales y a coordinar la política salarial con los objetivos de política macroeconómica.

El análisis de estos países pone de relieve la estrecha interdependencia entre modelo de mercado laboral y modelo de bienestar. En los países nórdicos, el empleo a tiempo parcial, aunque genera desigualdades de género, no se percibe como una fuente de inseguridad en los ingresos económicos porque es fundamentalmente voluntario y porque cuenta con el apoyo de políticas familiares y de conciliación, incluidos servicios a la dependencia. La política de igualdad de género, en el marco de un importante volumen de empleo público, explica la reducción de las desigualdades en los países escandinavos, lo que concuerda con el hallazgo de Esping-Andersen (2014).

Por el contrario, el empleo a tiempo parcial en los países del Sur y Este de Europa correlaciona con la demanda de redistribución y con el riesgo de pobreza, lo que afecta en mayor proporción a las mujeres. En estos países el empleo a tiempo parcial tiende a ser "marginal", no es voluntario y no está apoyado por políticas de conciliación ni políticas familiares. En cierta forma este tipo de contrato a tiempo parcial refleja un aspecto de los emergentes "working poor": personas que a pesar de tener empleo sus ingresos les sitúan en el umbral de la pobreza por falta de apoyo con políticas sociales.

\subsection{Factores individuales}

Finalmente, en relación a las variables de control (H3), hemos constatado que las mujeres reclaman más políticas pro-redistributivas que los hombres; pero dicha 
demanda varía en función de los modelos de bienestar. La variable sexo tiene más peso determinante cuando se analiza de forma aislada, pero cuando se combina con las variables contextuales pierde peso, lo que nos indica que las variables contextuales de los modelos de bienestar influyen en su comportamiento. Igualmente los desempleados, las personas con bajos niveles de estudios, los inmigrantes y los mayores de 49 años son los que demandan más políticas redistributivas porque tienen menos probabilidades de alcanzar ingresos económicos altos.

En contraste, aquellas personas que tienen alto nivel de estudios y se auto-posicionan en lugares altos de la escala social tienen menos predisposición hacia la política redistributiva que aquellos otros que se sitúan en bajos lugares de la escala social, tienen bajo nivel de estudios y perciben con incertidumbre sus ingresos económicos, lo que concuerda con lo hallado por Wren y Rehm (2014). El perfil joven con alto nivel de estudios tiende a preferir opciones individualistas y menos solidarias. Obviamente, esta diferencia de actitudes respecto a la redistribución tiene implicaciones en la formación de coaliciones y alianzas políticas para impulsar las políticas redistributivas que permiten mitigar las desigualdades que genera el mercado de trabajo.

\subsection{Discusión}

El principal problema asociado a la demanda de redistribución radica en la dualización y segmentación del mercado de trabajo, en el desempleo, crecimiento del empleo atípico y en la baja calidad del empleo emergente. Para los países del Sur de Europa la estructura económica genera un mercado laboral dual y segmentado que no es fácil transformar porque es un problemas de fondo y estructural (Banyuls et al., 2009). Quizás ante esta realidad del mercado de trabajo sea más realista y fácil responder con políticas sociales correctoras para aliviar la demanda de redistribución. Una posible respuesta es la Renta Mínima de Inserción, o ingreso garantizado, cuya idea está cada vez más extendida en Europa como respuesta a la consolidación del empleo atípico y del desempleo intermitente (que reflejan aspectos estructurales de los mercados de trabajo, Bosch et al., 2009).

El trabajo a tiempo parcial es también otra tendencia de los mercados de trabajo en Europa. A pesar de la menor percepción de riesgo que suscita en los países nórdicos, gracias a las políticas sociales y de bienestar, supone un factor de precarización del empleo, además de alimentar las desigualdades de género, por lo que cabría pensar en fórmulas más equitativas de distribución del empleo y del tiempo de trabajo, aparte del propio impulso de políticas sociales y de bienestar, como se pone de relieve en el modelo nórdico.

Finalmente no podemos olvidar las bondades del "círculo virtuoso" que se deriva del empleo público, cuyo nivel en los países del Sur de Europa está por debajo de la media de Europa occidental. La calidad que ofrece el empleo público constituye una columna vertebral para el modelo de mercado de empleo, así como para la asociación sindical y la consiguiente formación de coaliciones sindicales y políticas valedoras del Estado del Bienestar. 


\section{Bibliografía}

Crouch, C. (2014): "Introduction: labour market and social policy after the crisis", Transfer, 20 (1), pp. 7-22.

Cho, Y. (2014): "To Know Democracy is to live it. A Cross-National analysis of Democratic Understanding and political Support for Democracy", Political Research Quaterly, 67 (3), pp. 478-488.

Banyuls, J., F. Miguélez, A. Recio y E. Cano (2009): "The Transformation of Employment System in Spain: Toward a Mediterranean Neoliberlism?, en G. Bosch et al. (eds.), European Employment Models in Flux, New York, Palgrave Macmillan, pp. 247-269.

Borisov, V. y C. Simon (2006): "The role and fall of social partnership in postsocialist Europe: the Commonwealth of Independent States", Industrial Relations Journal, 37 (6), pp. 607-629.

Bosch, G., S. Lendorff, y J. Rubery (2009): "European Employment Models in Flux: Pressures for Change and Prospect for Survival and Revitalization", en G. Bosch et al., (eds.), European Employment Models in Flux, New York, Palgrave Macmillan, pp. 7-56.

Breznau, N. (2010): "Economic Equality and Social Welfare: Policy Preferences in Five Nations", International Journal of Public Opinion Research, 22 (4), pp. 458484.

Campillo, I. (2010): "Políticas de conciliación de la vida laboral y familiar en los regímenes de bienestar mediterráneos", Revista Política y Sociedad, 47 (1), pp.189213.

Carrasquer, P. y A. Martín Artiles (2005): “La política de conciliación de la vida laboral y familiar. Un aspecto de la política de empleo", Cuadernos de Relaciones Laborales, 23 (1), pp.131-150.

Dallinger, U. (2010): "Public support for redistribution: What explains cross-national differences", Journal of European Social Policy, 20 (4), pp. 333-349.

Esping-Andersen, G. (2000): Los fundamentos sociales de la sociedad post-industrial, Barcelona, Ariel.

Esping-Andersen, G. (2014): "Welfare regimes and social stratification", Journal of European Social Policy, 25 (1), pp. 124-134.

Galbraith, J. K. (1992): La cultura de la satisfacción, Barcelona, Ariel.

Gërxhani, K. y F. Koster (2012): "I'm not alone: Understanding public support for the welfare state", International Sociology, 27 (6), pp.768-787.

Gingrich, J. y B. Ansell (2012): "Preference in Context: Micro Preference, Macro Context, and the Demand for Social Policy", Comparative Political Studies, 45 (12), pp. 1624-1654.

Huber, E. y J.D. Stephens (2014): "Income inequality and redistribution in postindustrial democracies: demographic, economics and political determinants", Socio-Economic Review, 12 (2), pp. 245-268.

Jakobsen, T. y O. Listhaug (2012): "Issue ownership, unemployment and support for government intervention", Work, Employment and Society, 26 (3), pp.396-411. 
Jensen, C. (2012): "Two sides of the same coin? Left-wing government and labour unions as determinants of public spending", Socio-Economic Review, 20 (2), pp.217-241.

Jepsen, M. (2000): "What do we know about the link between low pay, gender and parttime?", Transfer, 6 (4), pp.673-686.

Karp, J., S. A. Banducci y S. Bowler (2003): "To Know It Is To Love It?. Satisfaction with Democracy in the European Union", Comparative Political Studies, 36 (3) pp.271-292.

Klammer, U. (2000): "A challenge for the Welfare State", Transfer, 6 (4), pp. 570-591.

Keller, B. y H. Seifert (2013): "Atypical employment in Germany. Forms, development, patterns", Transfer, 19 (4), pp.457-474.

Kjellberg, A. (2009): "The Swedish Ghent System and trade unions under pressure", Transfer, 15 (3-4), pp.481-504.

Larsen, C. A. (2008): "The institutional Logic of Welfare Attitudes", Comparative Political Studies, 41 (2), pp.145-168.

Martín Artiles, A., O. Molina y P. Carrasquer (2016): “¿Ruptura del compromiso igualitario para sostener el Estado del Bienestar en Europa?”, Reis, 154 (en prensa).

Mau, S.; J. Mewes y N. Schöneck (2012): "What determines subjective socio-economic insecurity? Context and class in comparative perspective", Socio-Economic Review, 10 (4), pp.683-704.

Menz, G. (2008): "Migration and the Welfare State", en C. Parsons y T. Smeeding (eds.), Immigration and the Transformation of Europe, Cambridge, Cambridge University Press.

Neher, F. (2011): Preferences for Redistribution across the World, Berlin, Frei Universität Berlin.

OIT (2014): Informe Sobre el Trabajo en el Mundo 2014”. Ginebra, OIT

Peetz, D. (2010): “Are individualistics attitudes killing collectivism?”, Transfer, 16 (3), pp.383-398.

Ponthieux, S. y P. Concialdi (2000): "Low pay and poor workers: a comparative study of France and USA", Transfer, 6 (4), pp.650-672.

Rueda, D. (2014): "Dualization, crisis and welfare state", Socio-Economic Review, 12 (2), pp.381-408.

Schwartz, S. (2007):"Universalism Values and Inclusiveness of Our Moral Universe", Journal of Cross-cultural Psychology, 38 (6), pp.711-728.

Schmidt-Catran, A. (2014): "Economic inequality and public demand for redistribution: combining cross-sectional and longitudinal evidence", Socio-Economic Review, Advance Access, doi: 10.1093/ser/mwu030.

Van Oorschot, W. (2008): "Solidatity towards immigrants in European welfate states", International Journal of Social Welfare, 17 (1), pp. 3-14

Van Oosrchot, W., T. Reeskens y B. Mealeman (2012): "Popular perception of welfare state consequences: a multilevel, cross-national analysis of 25 European countries", Journal of European Social Policy, 22 (2), pp. 181-197.

Wren, A. y Ph Rehm (2014): "The end of consensus? Labour market developments and the politics of retrenchment", Socio-Economic Review, 12 (2), pp.409-435. 


\section{Anexos}

Tabla 4: Regresión multinivel: factores influyentes en la incertidumbre

\begin{tabular}{|c|c|c|c|c|c|}
\hline \multirow[t]{2}{*}{$5^{\circ}$ Paso } & \multicolumn{2}{|c|}{$\begin{array}{l}\text { Modelo } 1 . \\
\text { Individuales }\end{array}$} & \multicolumn{3}{|c|}{$\begin{array}{l}\text { Modelo } 2 . \\
\text { Individuales y contextuales }\end{array}$} \\
\hline & B & Sig. & $\mathrm{B}$ & & \\
\hline (Constante) & 2,767 & $0,000 * * *$ & 46,796 & ,043 & $*$ \\
\hline Mujer &, 082 &, $000 * * *$ &, 082 &, 000 & $* * *$ \\
\hline Edad &,- 001 & $\begin{array}{r}, 851 \\
(\mathrm{~ns})\end{array}$ & & & \\
\hline Nivel Educación &,- 118 &, $000 * * *$ &,- 118 &, 000 & $* * *$ \\
\hline Reducir desigualdades & ,131 &, $000 * * *$ &, 131 &, 000 & $* * *$ \\
\hline Posición en la sociedad &,- 186 & $0,000 * * *$ &,- 186 & 0,000 & $* * *$ \\
\hline Tasa Empleo Público & & &,- 050 & ,308 & $\mathrm{ns}$ \\
\hline Tasa Desempleo & & & ,423 & 244 & ns \\
\hline Tasa Contratos temporales & & &,- 221 &, 120 & ns \\
\hline Tasa Tiempo parcial sobre total & & &,- 150 &, 045 & $*$ \\
\hline Tasa Working poor & & &, 627 & ,119 & ns \\
\hline Índice Gini & & &,- 682 & , 102 & ns \\
\hline Gasto Protección Social (\% Pib) & & & 232 & 104 & $\mathrm{~ns}$ \\
\hline Gasto en Pensiones (\% Pib) & & & ,364 & 225 & ns \\
\hline
\end{tabular}




\begin{tabular}{|l|c|c|c|c|c|}
\hline & \multicolumn{2}{|l|}{$\begin{array}{l}\text { Modelo 1. } \\
\text { Individuales }\end{array}$} & \multicolumn{3}{l|}{$\begin{array}{l}\text { Modelo 2. } \\
\text { Individuales y contextuales }\end{array}$} \\
\hline & B & Sig. & B & & \\
\hline $\begin{array}{l}\text { \% Personas } \\
\text { que reciben cualquier tipo pensión }\end{array}$ & & &,- 459 &, 043 & $* * *$ \\
\hline Pib per cápida en paridad compra & & &,- 099 &, 020 & $*$ \\
\hline $\begin{array}{l}\text { Pensión por desempleo, } \\
\text { Euros por habitante }\end{array}$ & & &,- 005 &, 036 & $*$ \\
\hline Desempleo larga duración & 459 & & 460,000 & & \\
\hline R &, 211 & &, 211 &, 211 & \\
\hline R cuadrado & 33.357 & & 33.357 & & \\
\hline N & & & 17 & & \\
\hline N países & & & $-1,125$ & \\
\hline
\end{tabular}

Regresión lineal por el método "hacia atrás": Variables introducidas y eliminadas en los sucesivos pasos. Las variables eliminadas son el índice de Gini, la tasa de impuestos... Las variables no significativas, pero que permanecen en el modelo son: el desempleo de larga duración, el gasto en pensiones, el empleo público, el desempleo, el gasto en protección social, el índice de Gini, los Working Poors y el gasto en pensiones.

Significación: * ${ }^{*} \mathrm{q}>, 050 ; * * \mathrm{pq}>, 010 ; * * * \mathrm{pq}>, 001$.

Fuente: Elaboración propia ESE 2012. 
Tabla 5: Análisis multinivel

Variables determinantes en la demanda de redistribución

\begin{tabular}{|c|c|c|c|c|c|c|}
\hline & \multicolumn{2}{|c|}{$\begin{array}{l}\text { Coeficientes no } \\
\text { estandarizados }\end{array}$} & \multirow{2}{*}{ Sig. } & \multicolumn{2}{|c|}{$\begin{array}{l}\text { Coeficientes no } \\
\text { estandarizados }\end{array}$} & \multirow{2}{*}{ Sig. } \\
\hline & B & $\begin{array}{l}\text { Std. } \\
\text { Error }\end{array}$ & & B & $\begin{array}{l}\text { Std. } \\
\text { Error }\end{array}$ & \\
\hline (Constante) & 3,207 &, 156 &, $000 * * *$ & 4,536 & 2,8 & $\begin{array}{l}, 105 \\
\text { (ns) }\end{array}$ \\
\hline Género: Mujer & ,289 & ,043 &, $000^{* * *}$ & 0,109 & 0,009 &, $000^{* * *}$ \\
\hline Edad &, 123 & ,016 &, $000 * * *$ & 0,052 & 0,004 &, $000 * * *$ \\
\hline Nivel Estudios &,- 012 &, 029 & $\begin{array}{l}, 694 \\
\text { (ns) }\end{array}$ & $-0,068$ & 0,006 &, $000^{* * *}$ \\
\hline $\begin{array}{l}\text { Percepción ingresos: } \\
\text { certidumbre e incertidumbre }\end{array}$ & ,185 & ,031 &, $000 * * *$ & 0,195 & 0,006 &, $000^{* * *}$ \\
\hline $\begin{array}{l}\text { Posición social: } \\
0=\text { baja y } 10=\text { alta }\end{array}$ &,- 077 & ,015 &, $000^{* * *}$ & $-0,054$ & 0,003 &, $000^{* * *}$ \\
\hline Gasto en Pensiones en $\%$ Pib & & & & $-0,992$ & 0,226 &, $000 * * *$ \\
\hline Autoempleo & & & & $-0,206$ & 0,104 &, $048^{*}$ \\
\hline $\begin{array}{l}\text { Pensión por desempleo, } \\
\text { Euros por habitante }\end{array}$ & & & & $-0,004$ & 0,002 &, $019 *$ \\
\hline Contratos temporales & & & & 0,144 & 0,065 &, $028^{*}$ \\
\hline Desempleo & & & & $-0,499$ & 0,137 &, $000 * * *$ \\
\hline $\begin{array}{l}\text { Trabajo a tiempo parcial } \\
\text { (\% sobre total empleo) }\end{array}$ & & & & $-0,128$ & 0,045 &, $004 * *$ \\
\hline $\begin{array}{l}\text { Riesgo de Pobreza } \\
\text { (Menos } 60 \% \text { ingresos) }\end{array}$ & & & & 0,577 & 0,172 &, $001 * * *$ \\
\hline $\begin{array}{l}\text { Gasto Protección Social } \\
(\% \text { Pib })\end{array}$ & & & & 0,439 & 0,139 &, $002 * *$ \\
\hline
\end{tabular}




\begin{tabular}{|c|c|c|c|c|c|c|}
\hline & \multicolumn{2}{|c|}{$\begin{array}{l}\text { Coeficientes no } \\
\text { estandarizados }\end{array}$} & \multirow{2}{*}{ Sig. } & \multicolumn{2}{|c|}{$\begin{array}{l}\text { Coeficientes no } \\
\text { estandarizados }\end{array}$} & \multirow{2}{*}{ Sig. } \\
\hline & B & $\begin{array}{l}\text { Std. } \\
\text { Error }\end{array}$ & & B & $\begin{array}{l}\text { Std. } \\
\text { Error }\end{array}$ & \\
\hline $\begin{array}{l}\text { Diferencias de género absoluto } \\
\text { en riesgo de pobreza }\end{array}$ & & & & 0,183 & 0,05 &, $000 * * *$ \\
\hline $\mathrm{R}$ &, $333^{\mathrm{a}}$ & & &, $268^{\mathrm{h}}$ & & \\
\hline R cuadrado &, 111 & & & 0,072 & & \\
\hline $\mathrm{N}$ casos & & & & 17 & & \\
\hline $\mathrm{N}$ & 33.801 & & & 33.801 & & \\
\hline
\end{tabular}

Regresión lineal por el método "hacia atrás": Variables introducidas y eliminadas en los sucesivos pasos de 1 a 8 por no ser significativas: Empleo público, empleo en empresa privada, desempleo de larga duración, número de personas que reciben cualquier tipo de pensión; Pib per cápita; tasa de impuesto e índice de Gini.

Significación: ${ }^{*} \mathrm{pq}>, 050 ; * * \mathrm{pq}>, 010 ; * * * \mathrm{pq}>, 001$.

Fuente: Elaboración propia ESE 2012. 